\title{
PerCursos
}

\section{Uma Lisboa só dele(s). Processos artivistas de recriação de paisagens sonoras contemporâneas}

\begin{abstract}
Resumo
Este artigo expõe a trajetória de um músico português - Tó Trips - e da sua última banda - os Dead Combo - no intuito de fundir um percurso musical com uma paisagem sonora na linha da conceitualização de Schafer (2012). Socorrendo-nos, em termos metodológicos, de uma história de vida e de materiais documentais, iremos estabelecer uma sincronia entre cidade, sons, criação musical e intervenção artística. Os Dead Combo e Tó Trips são, no quadro deste artigo, os (re)criadores ativos de Lisboa, permitindo, simultaneamente, estabelecer algumas asserções sobre o valor do som e da música como carburantes de identidades coletivas e individuais; e sobre a potenciação da construção de imaginários simbólicos e afetivos face a um espaço urbano na senda de Frith (1996). Num processo que alguns designam como spatial turn (STAHL, 2004) nas últimas décadas, iremos evidenciar que a globalização parece ter renovado a ênfase no local, encorajando reconstruções identitárias através do surgimento de novas expressões artísticas de vínculo à cidade e, portanto, de uma reimaginação da cidade, partindo de uma produção artística territorialmente ancorada, vivida e sentida. E tal ênfase parece revestirse de uma urgência crítica nestes tempos distópicos.
\end{abstract}

Palavras-chave: paisagens sonoras; artivismos; Dead Combo; Tó Trips; Lisboa.

\author{
Paula Guerra \\ Professora e Investigadora da \\ Faculdade de Letras e do \\ Instituto de Sociologia da \\ Universidade do Porto, Portugal. \\ Professora Associada Adjunta do \\ Griffith Center for Social and \\ Cultura Research, Austrália. \\ Portugal \\ pguerra@letras.up.pt \\ orcid.org/0000-0003-2377-8045
}

\footnotetext{
Para citar este artigo:

GUERRA, Paula. Uma Lisboa só dele(s). Processos artivistas de recriação de paisagens sonoras contemporâneas. PerCursos, Florianópolis, v. 22, n.50, p. 15 - 42, set./dez. 2021.
}

DOI: 10.5965/1984724622502021015

http://dx.doi.org/10.5965/1984724622502021015 


\title{
A Lisbon of his own. Artivist processes of recreation of contemporary soundscapes
}

\begin{abstract}
This article exposes the trajectory of a Portuguese musician - Tó Trips - and his last band - Dead Combo - in order to merge a musical path with a sound landscape in the line of Schafer's concetualization (2012). By helping us, in methodological terms, with a life history and documentary materials, we will establish a synchrony between city, sounds and social actors. Dead Combo and Tó Trips are, in the framework of this article, the (re)creators of a sound landscape of Lisbon, allowing, simultaneously, to establish some assertions about the value of sound and music as fuels of collective and individual identities; and the potentiation of the construction of symbolic and affective imaginaries in the face of a certain urban space in Frith's path (1996). In a process that some call spatial turn (STAHL, 2004) in the last decades, we will show that globalization seems to have renewed the emphasis on the local, encouraging reconstructions of identities through the emergence of new expressions of attachment to the city and, therefore, a re-imagination of the city, starting from an artistic production territorially anchored, lived and felt. And such an emphasis seems to be assuming a critical urgency in these pandemic times.
\end{abstract}

Keywords: soundscapes; artivisms; Dead Combo; Tó Trips; Lisbon. 


\section{1 poder das palavras e dos sons}

Pensar sobre as mudanças sonoras que decorreram no seguimento da pandemia mundial da COVID-19 foi o nosso ponto de partida para a elaboração deste artigo. Um pouco por todo o mundo vivenciaram-se momentos de confinamento e, como tal, os sons, os cheiros e as vivências que se substantificavam nas cidades e na vida urbana, tornaram-se uma memória nostálgica. O silêncio e o medo imperavam nas ruas, enquanto que a música - nas nossas casas - levava-nos para outros locais de forma subconsciente, através de composições melódicas que nos faziam lembrar momentos marcantes da vida associados a espaços. Neste sentido, é impreterível optar por uma abordagem que revele o urbano como um espaço social relacional, uma vez que este se assume como um cenário-tipo de um conjunto de relações e de posições que pautam a vida dos indivíduos, aspecto esse que é potenciado pela criação e (re)produção artística, mais concretamente, a musical. Os sons mapeiam os nossos espaços, as nossas vidas nas cidades como bem demonstra Carlos Fortuna (1999).

Dado que a indústria musical tem vindo a ser alvo de um profundo processo de reconfiguração devido aos efeitos pandêmicos que se têm sentido, algo tanto mais evidente quando pensamos no contexto português, também as suas relações com os territórios e com as cidades têm vindo a ser objeto de transformações, no sentido em que emergem novos negócios, novos agentes e novos modelos de criação, produção e disseminação artística, criando novas e diversificadas redes e conexões em outros espaços. Então, o presente artigo visa uma apresentação de algumas reflexões em torno das produções musicais, focando a trajetória do músico Tó Trips ${ }^{1}$. Através da sua história de vida ${ }^{2}$ enquanto músico em Lisboa, procuraremos dar relevo aos Dead Combo ${ }^{3}$, com o

\footnotetext{
${ }^{1}$ Tó Trips nasceu em Lisboa em 1966. No presente é designer (assina como Mackintóxico) e músico. Trata-se de um guitarrista português com uma trajetória originária nos anos 1980 quando fundou e colaborou em bandas de rock alternativo com sonoridades próximas do punk, pós-punk e no wave como os Amen Sacristi, os Lulu Blind e os Santa Maria Gasolina em Teu Ventre!. No início do milênio, cofundou os Dead Combo. Em 2009, Tó Trips lançou o seu primeiro álbum solo, o Guitarra 66. Como compositor e instrumentista, solo ou nas bandas, Tó cria uma atmosfera de mescla híbrida da guitarra de Carlos Paredes, da música da boemia lisboeta, da tradição cubana vista por Marc Ribot, do western spaghetti de Ennio Morricone e do rendez-vous ibero-árabe do flamenco. Tó Trips é, reconhecidamente, dos músicos portugueses mais interessantes das últimas décadas; o artista tem marcado presença nos mais inovadores projetos do imaginário alternativo musical.

${ }^{2}$ Este artigo decorre de um projeto de investigação desenvolvido entre 2005 e 2010 e intitulado "Culturas
} 
intuito de fornecermos uma visão sobre a cidade de Lisboa e a sua paisagem sonora, retratada a partir dos seus acordes. Tal como para Fausta Cardoso Pereira (2020), a discografia dos Dead Combo transporta-nos para e por Lisboa. Falar de Tó Trips e dos Dead Combo é falar de Lisboa: dos seus sons, dos seus cheiros, dos seus espaços, das suas personagens. Talvez resida aqui a urgência dessa abordagem situada neste tempo pandêmico para que não nos esqueçamos da fisicalidade da vida.

Assim, almejamos mostrar uma cidade como um discurso subjetivo que perfura as lógicas do artivismo. Vejamos que através do cruzamento entre a arte e o ativismo (GUERRA, 2019), pretendemos dar conta de um posicionamento político por parte de Tó Trips e dos Dead Combo face à cidade. Nesse caso, enunciamos que de forma diacrônica e sincrônica, as músicas e as produções artísticas de Tó e da banda destacam as lógicas de ação, de criação, de resistência e de interdependência que pautam, de forma marcada, as ligações entre música e território. Entre poder e contestação. Entre a luta e a denúncia. Procuramos estabelecer uma relação entre o seu percurso musical, artístico e profissional, ao mesmo tempo em que tentamos conferir um vislumbre à importância da

urbanas e modos de vida juvenis: cenários, sonoridades e estéticas na contemporaneidade portuguesa (SFRH/BD/24614/2005)" no âmbito do Instituto de Sociologia da Universidade do Porto coordenado pela autora deste artigo e financiado pela Fundação de Ciência e Tecnologia. Este projeto deu origem à Tese de Doutoramento em Sociologia - A instável leveza do rock. Génese, dinâmica e consolidação do rock alternativo em Portugal (1980-2010). Porto: Faculdade de Letras da Universidade do Porto (AUTOR 1, 2010). Para mais detalhes consultar: https://repositorio-aberto.up.pt/handle/10216/56304?mode=full. No âmbito deste projeto, realizamos uma história de vida de Tó Trips que - neste artigo - se assume como corpus analítico de base. Posteriormente, e no âmbito do projeto "Portugal ao Espelho: identidade e transformação na literatura, no cinema e na música popular", financiado pela Fundação Calouste Gulbenkian, e desenvolvido entre 2014 e 2016, continuamos a pesquisa em torno de Tó Trips e dos Dead Combo (ver https://portugalaoespelho.wordpress.com). Recentemente, e no curso do desenvolvimento do projeto de investigação "Juventude e artes da cidadania: práticas criativas, cultura participativa e ativismo", também financiado pela Fundação de Ciência e Tecnologia (PTDC/SOC - SOC/28655/2017) pudemos concluir esta abordagem. Agradecemos ao Professor Jorge de La Barre e ao Tó Trips todo o incentivo à escrita deste artigo.

${ }^{3}$ Dedico este artigo a Pedro Gonçalves - cofundador e companheiro de Trips nos Dead Combo - que morreu em 4 de dezembro de 2021, em Lisboa, aos 51 anos. Os Dead Combo (2002-2020) eram compostos por Tó Trips (guitarras) e Pedro Gonçalves (contrabaixo, kazoo, melódica e guitarras). Lançaram em 2004 o seu primeiro álbum e desde logo se fizeram notar por uma sonoridade inovadora sem vozes, somente com instrumentos. As suas principais influências são o fado, o rock, os blues e o folk. Anunciaram o seu término em 2020. O programa "No Reservations Lisboa", de Anthony Bourdain, lançou os Dead Combo para o top do iTunes mundial em 2012. Contaram com sete álbuns de estúdio: Vol.1 (2004); Vol. 2 - Quando A Alma Não É Pequena (2006); Guitars From Nothing (2007); Lusitânia Playboys (2008); Lisboa Mulata (2011); A Bunch of Meninos (2014); e Odeon Hotel (2018). Na sua discografia também pontuam dois álbuns ao vivo - Live Hot Clube (2009) e Live at Teatro São Luiz (2014); e um DVD intitulado Dead Combo \& Royal Orquestra das Caveiras (2010). São uma das mais emblemáticas manifestações de música urbana deste milênio em Portugal. Para mais informações: https://deadcombo.net/. 
música - na apreciação do artista - enquanto banda sonora da vivência na cidade e, claro está, alcançar a presença do urbano nos álbuns da banda. Todos esses elementos se ligam a uma nova linguagem, que mistura arte e ativismo social: o artivismo. Tem como influências o graffiti, a arte urbana, o do-it-yourself punk, o situacionismo e o seu palco preferido: o espaço urbano.

Defendemos aqui que a vida de Tó e dos seus projetos se ancora a uma constante de resistências levadas a cabo e materializadas nas práticas, tais como o DIY (do-ityourself), pelas estéticas adotadas contra-hegemônicas, mas também nos discursos que permeiam a sonoridade que compõem as soundtracks dos álbuns, referentes à crise. $O$ que pretendemos destacar é que as escolhas de Tó Trips e dos Dead Combo, bem como os seus sons, representam a resistência de uma população residente num país que atravessou no pós-democracia profundas crises econômicas e sociais. Nesse sentido, o seu artivismo possui uma dupla hermenêutica entre os modos de resistência, profundamente associados a um contexto do Norte Global, mas também os modos de existência são uma lógica a ter em consideração pois, tal como acontece em países do Sul Global (GUERRA, 2021) onde estas formas de atuação não são a única alternativa para fazer face às dinâmicas vivenciais e quotidianas. Tendo tais questões em mente, organizamos o artigo em torno de uma narrativa artística e musical, auto e hétero construída de uma realidade urbana, que foi perspectivada através do uso de uma abordagem metodológica de caráter predominantemente qualitativo.

\section{Um homem atravessa Lisboa na sua querida bicicleta ${ }^{4}$}

Patenteia-se um processo de valorização social da temática territorial e urbana no campo sociológico (RODRIGUES, 1999). E é dentro deste contexto transformativo que as ofertas e as produções culturais assumem toda a pertinência, pois a música, os seus objetos/artefatos e sons correlacionados emanam dos espaços: destacando "as apreciações acerca da dialética entre estetização do quotidiano e quotidianização das

\footnotetext{
${ }^{4}$ Título de uma canção dos Dead Combo inserida no álbum Guitars from Nothing de 2007 lançado pela Rastilho Records.
} 
estéticas - de facto, o espaço urbano é simultaneamente constituído e constitutivo desta operação" (GUERRA et al., 2018. p. 188). É nessa interseção entre espaço e prática cultural que se situam os espaços de fruição musical, proporcionando uma visão sobre a cidade como sendo pluridimensional pois, como afirma Featherstone (1995), as cidades pós-modernas são auto-conscientes cultural e imageticamente na justa medida em que se assumem como o centro do consumo, bem como o pináculo da influência dos estilos de vida, da vida quotidiana e das atividades de lazer.

A produção musical, no contexto urbano, ocupa um papel de relevo. Esta expressão artística - e já estabelecendo uma ponte com os Dead Combo e com Tó Trips detém a habilidade de vincular identidades coletivas e individuais, promovendo uma reconfiguração no modo de interação entre o global e o lobal (HALL, 2003) e originando um processo de hibridização cultural (MARTIN-BARBERO, 2006; REGEV, 2013). Esta miríade de influxos acabou por influenciar o aumento de abordagens relacionadas com as chamadas "cidades criativas". Deste modo, tal como nos refere Reis (2011), encaramos Lisboa como uma cidade que se destaca pelas suas conexões e que tem na cultura o alicerce da criatividade e do diferencial social, econômico e urbano: é uma cidade focada na construção de narrativas interligadas a setores artísticos e culturais, como é o caso da música, e que visam o envolvimento dos residentes e dos turistas. Mais ainda, Lisboa - a par da cidade do Porto - tem sido um exemplo paradigmático de como a música pode ser utilizada enquanto ferramenta para o desenvolvimento local, gerando impactos nos mais diversos níveis estruturais. Por outras palavras, pretendemos estabelecer Lisboa como uma cidade musical que se desenvolve a partir de uma rede informada, ao mesmo tempo que a perspectivamos como um polo agregador de cenas musicais. Lisboa é marcada por uma miríade de cenas musicais relacionadas com diversos gêneros musicais e que dão origem a uma territorialidade sônica. Nesta linha, Herschmann e Fernandes (2016) alertam para o reconhecimento da importância das sonoridades que fazem parte e que compõem os quotidianos (DENORA, 2004), bem como os processos de (re)territorialização a elas associados.

As cidades, a cultura e a economia criativa são amplamente entendidas como interdependentes, surgindo interligadas num rol de iniciativas, discursos e agendas, não 
raras vezes contraditórios. A música, enquanto linguagem e manifestação cultural universal, é um elemento-chave nesta equação. E o é já há muito tempo: basta lembrar Manchester ou Liverpool. Sara Cohen (1991) fez um trabalho seminal acerca desta última cidade, mostrando a constituição de uma cena musical intensa imersa na cidade onde as atividades formais e informais de música, os produtores, os artistas, os clubs estão interligados. Também para o Brasil, os trabalhos de Herschmann (2011, 2012, 2013), são determinantes para que possamos compreender o papel exercido pela música nas cidades e nos indivíduos, nomeadamente ao nível dos consumos, das lógicas de usufruição, consumo e produção, mas também na senda do desenvolvimento local, isto é, a música enquanto ativismo e artivismo. É, afinal, nesta premissa que assenta o conceito de cidades musicais que, nos últimos anos, tem marcado presença com especial intensidade não apenas nos discursos de múltiplos intermediários, como atores políticos, outros representantes locais e consultores internacionais (BENNETT, 2020; TERRIL et al., 2015), mas também no meio acadêmico, através de diversas pesquisas desenvolvidas no âmbito das ciências sociais (BALLICO; WATSON, 2020; BAKER, 2019; BENNETT; GUERRA, 2019; HOMAN, 2016). São múltiplos os significados atribuídos ao conceito de cidades musicais, e diversas as abordagens através das quais ele é utilizado.

A relação entre a música e a cidade é histórica. Aliás, tal como Autor 1 (2019) enuncia, a cidade, enquanto local de lutas por visibilidade e enquanto palco de afirmação identitária, destaca-se como um locus de atividade artística com propósitos sociais e reivindicativos. A música e os sons dos Dead Combo e do Tó Trips desempenham um papel crucial na resistência e na subversão de um status quo, propondo diferentes visões sobre a realidade social lisboeta de uma época. Assim, é quase impossível desassociar os Dead Combo e o Tó Trips e a cidade, mas também desassociá-los do artivismo, especialmente pelo fato de nunca se terem tratado de produções artísticas panfletárias e de propaganda ideológica, mas sim de conteúdos com uma verdadeira mensagem que, apesar do seu sucesso, nunca perderam o seu cunho interventivo e a sua identidade (SÁ; STRAW, 2011).

A cidade é, pois, terreno fértil para a fecundação e para a incubação de novas tendências, novos produtos e novos princípios (ethos) culturais assentes numa economia 
da noite (NOFRE, 2019). É no interstício desses movimentos que surgem as cenas, tal como nos referem Sá e Straw (2011), presas a uma lógica de sociabilidade e de conexão com a cidade. Assume-se crucial o conceito de cena (BENNETT; PETERSON, 2004) enquanto construção social balizada pelas redes e padrões de interações que ocorrem num dado espaço-tempo. Uma cena diz respeito a um cluster de atividades sociais e culturais sem possuir fronteiras rígidas, mas uma vinculação a um espaço de interação. As cenas podem distinguir-se entre si pela sua localização geográfica, pelo tipo de produção cultural que a identifica ou pelas atividades sociais que a animam (SÁ; JANOTTI, 2013). A grande virtude do conceito assenta no fato de nos fazer um convite ao mapeamento do território urbano, a novas formas, a novos usos, a novas semióticas, a novas relações. Ela pode ser definida como uma comunidade significante de sons, imagens, lifestyles, estéticas, entre outras. O termo cena é uma forma de expressar a teatralidade da cidade ou a capacidade de a cidade gerar imagens das interações. Capta, por isso, o sentido de agitação da cidade, as sociabilidades quotidianas.

Ao mesmo tempo e em diferentes contextos geográficos e socioculturais, o conceito de cidades musicais tem sido associado a estratégias de marketing urbano e inserido em esquemas de desenvolvimento internacional, de que é exemplo claro a rede de Cidades de Música da UNESCO (https://citiesofmusic.net/), inserida na Rede de Cidades Criativas. Desde 2006, têm vindo a ser agregadas várias cidades que identificaram a música como elemento marcante na definição da sua identidade. Em cada uma delas, as autoridades locais comprometem-se a apoiar projetos locais que celebrem o seu patrimônio musical e a organizar eventos nacionais e internacionais em torno da música. Trata-se de mobilizar a cultura, e em específico a música, pelo seu potencial de criação e regeneração de imagens e de narrativas urbanas.

\section{A paisagem Elétrica Cadente de Lisboa}

O conceito de paisagem sonora [soundscape] encontra-se intimamente ligado a processos históricos de mediação e de mudanças tecnológicas que tornam possível atos distintos de ouvir o som (SAMUELS et al., 2010). Aliás, o conceito de soundscape pode ser 
rastreado até Schafer (1977), que o introduziu dentro de um contexto de circulação largado que apelidou de "total apreciação do ambiente acústico" (SCHAFFER, 1994, p. 4). Desta feita, esse conceito é similar a uma paisagem propriamente dita, na medida em que procura conter em si mesmo tudo aquilo a que os nossos sentidos foram expostos em determinado ambiente sonoro, neste caso, em cada cidade percorrida; porém, tal como Samuels et al. (2010) afirmam, também o próprio conceito de paisagem é controverso pois é fruto de contradições naturais e culturais, do improvisado e do deliberado: "como a paisagem é constituída por histórias culturais, ideologias e práticas de ver, a paisagem sonora implica a audição como uma prática cultural” (SAMUELS et al., 2010, p. 330).

Atualmente, diversos autores referem que o conceito de paisagem sonora é amplo, no sentido em que aloja o ambiente sonoro que caracteriza determinado local, mas também a resposta individual a esse mesmo ambiente. Sendo difícil de caracterizar e de descrever, alguns estudos têm sido feitos com o intuito de percecionar as dimensões subjetivas das paisagens sonoras. Job et al. (1999) propõem um modelo alicerçado numa análise de todos os elementos que compõem uma paisagem sonora, desde a paisagem ambiental (o som em si mesmo) à paisagem psicológica ou cognitiva (a das subjetividades individuais). Essa relação entre som, espaço e indivíduo é o mote para este artigo, uma vez que afirmamos a existência de uma relação de proximidade e de interdependência entre o artista/banda, o som - a música e a produção musical - e a cidade que aqui pode ser entendida como a paisagem (SCHAFFER, 1994) no seu sentido lato.

Apesar da sua proeminência no espaço urbano, as paisagens sonoras que pautam as cidades têm recebido pouca atenção analítica, algo que pretendemos colmatar com a elaboração deste artigo. A música da cidade é omnipresente: na verdade "estamos envoltos pelo som, ele forma uma teia contínua à nossa volta. Não podemos desligar o som automaticamente. Simplesmente não estamos equipados com tampões auriculares." (MCLUHAN; FIORE, 1989, p. 111). Beer (2007, p. 848) enuncia a possibilidade de se identificarem cinco pontos de contato entre a música e a cidade: o gênero musical urbano; a composição urbana; lírica e conexões experimentais com os lugares; os lugares de consumo; a música móvel/digital. Partindo desses pontos de contaco, iniciamos um processo de estreitamento, indo ao encontro do nosso objeto empírico. De modo breve, 
destacamos o primeiro ponto enunciado anteriormente que se refere à própria composição urbana como modo de composição musical, pois diz respeito aos sons do quotidiano (DENORA, 2004), em que as cidades são tidas como fontes de composição, isto é, pensando no caso dos artistas, a cidade, a vida na cidade e o urbano são o mote para a criação artística. Além disso, também a lírica e as conexões experimentais se arcam de relevo, uma vez que se relacionam diretamente com os significados que são produzidos face ao espaço urbano, tendo-o como lugar de pertença. As músicas - tal como veremos no discurso de Tó Trips - têm uma ligação direta com lugares comuns e próximos. Assim, as experiências musicais estão intimamente ligadas aos lugares em que são vivenciadas (GILLETT, 1970), daí que seja necessário pensar no papel que a música desempenha na narrativa do lugar (BENNETT, 2004).

Deste modo, entendemos a música como um veículo e objeto das movimentações sociais contemporâneas, quase como se esta se tratasse de uma banda sonora da resistência, mas também podem ser encaradas como um fator motivacional para juntar as pessoas nas ruas e, essencialmente, para contribuírem para uma redefinição de eixos políticos. O nosso objeto de estudo atua, assim, sobre as suas lutas, estando as mesmas patentes nos reportórios. Tal como Sànchez e Pàmpols (2020) destacam no caso da Arab Spring, os temas atuais na música popular são reivindicações, altamente politizadas que são também elementos essenciais para o estabelecimento de discursos e narrativas próprias, no sentido em que a música pode ser tida como um produto do conhecimento local e sensibilidades, bem como uma forma de território cultural independente. É o conhecimento local que atua como a base para a ação social, pois expressa uma ação política e uma reflexão das tensões e das contradições nas paisagens urbanas.

\section{Os Verdes Anos de um Rocker em Lisboa}

Mas eu tinha a mania de vir para casa sempre a assobiar e uma das vezes vinha a assobiar os "Verdes Anos" e se tu assobiares os "Verdes Anos" de forma lenta, aquilo parece-te um western. Se tu assobiares os "Verdes Anos" [e começa a assobiar], se tu assobiares isto devagar, pode parecer

\footnotetext{
${ }^{5}$ Trata-se de uma canção de Carlos Paredes, um compositor e guitarrista português. A canção foi lançada em 1967 no seu álbum "Guitarra portuguesa".
} 
um western. Então fiz esse exercício na guitarra. Depois a partir daí, sei lá, misturei um bocado com sonoridade portuguesa. (Tó, 54 anos, Designer Gráfico, Músico e Compositor, 12. Ano de Escolaridade, Lisboa. Informação verbal)

Tó nasceu em Lisboa, na freguesia do Castelo em 1966, estando registado em Benfica onde morou durante a sua infância e juventude, numa rua entre a Praça de Espanha e Sete Rios. Tendo nascido no seio de uma família oriunda de um meio rural “os meus pais são pessoas que vieram do campo para Lisboa. O meu pai é de perto de Castelo Branco e a minha mãe é da Covilhã e vieram novos para cá. Depois cá conheceram-se e casaram" (informação verbal) - a sua infância é marcada por esta proveniência, aliás muito comum a várias lisboetas nos anos 1960 - “é o tipo de família que vem do campo para a cidade. Aqui, Lisboa é muito provinciana nesse sentido [...]. Por isso é que Lisboa tem muitos quintais com hortas, nespereiras e figueiras" (informação verbal). O seu pai era comerciante, tendo primeiramente uma mercearia de bairro que se transformou em café; a mãe casou como dona de casa tendo posteriormente obtido um curso de costura e trabalhado inicialmente por conta de outrem, tendo depois montado um negócio próprio. Tó identifica o seu lugar de classe de origem como situado nas “chamadas classes médias baixas urbanas, isto é, não era pessoal que ganhava muito dinheiro, mas também... dava para safar" (informação verbal). Tó tem ainda uma irmã, cinco anos mais nova, que é editora de vídeo ligada à montagem e pós-produção de imagem.

A infância de Tó é perspectivada como tendo sido muito feliz, sendo de destacar que o agente social em causa confere, também por isso, especial destaque ao 25 de abril de 1974, na medida em que tinha oito anos e pôde testemunhar todo um conjunto de mudanças sociais e políticas assinaláveis. A sua adolescência e juventude foram marcadas por uma forte ética para o trabalho, no sentido da necessária valorização do trabalho como meio para alcançar fins que poderiam ir desde o lúdico à realização pessoal. Tó explica essa lógica a partir das origens dos pais e do seu posicionamento políticopartidário, situado na esfera social-democrata sob a égide de Sá Carneiro, contrário ao seu próprio posicionamento político situado bem mais à esquerda. Não obstante este relativo confronto ideológico, Tó valoriza todo o conjunto de valores e orientações éticas 
transmitidos pelos pais, que mais tarde viriam a marcar profundamente as suas produções musicais, bem como os projetos dos quais fez parte, como por exemplo os Dead Combo.

A frequência do Liceu D. Pedro $V$ até aos 12 anos, tido na altura como o "liceu da porrada e da droga" (informação verbal), foi importante para uma abertura de Tó a determinadas dinâmicas de cultura juvenil emergentes em Portugal. No que toca à sua sociabilização musical, a frequência da igreja, através da catequese, potenciou um primeiro contato com a música, sendo aí que Tó pega pela primeira vez numa guitarra elétrica (aos 12/13 anos). Portanto, a igreja apresenta-se como contexto primordial de socialização musical que funcionou como combustão da sua paixão pela guitarra. Nesta mesma altura, já contactava com outras redes de sociabilidade, nomeadamente os amigos da rua e do jardim Padre Francisco Alves (que funcionava como ponto de encontro), que também estimularam essa prática musical, inclusivamente através da criação de bandas, bem como os primeiros contatos com as drogas leves. A relação de Tó com as drogas foi um processo de proximidade e, em simultâneo, de distanciamento.

Ao princípio era aquela coisa local, de bairro, de liceu, do jardim Padre Francisco Alves (que a gente parava no jardim), mas depois começámos a conhecer pessoal de outras bandas, que eram bandas sei lá de Alvalade, de Campo de Ourique, sei lá... Lembro-me de ver os More República Maçónica, por exemplo, no Rock Rendez Vous. Depois começas a conhecer essas pessoas naturalmente, chegas lá e: «Parabéns!». E depois começas: «Ei, vamos tocar ali».... (Tó, História de Vida 1, 54 nos, Designer Gráfico, Músico e Compositor, 12..$^{\circ}$ Ano de Escolaridade, Lisboa informação verbal)

Ainda no que diz respeito aos tempos de Liceu, é de apontar que foi nessa época que Tó formou a primeira banda, os Amen Sacristi ${ }^{6}$, constituídos pelos amigos da igreja, chegando mesmo a ensaiar no Estúdio Som, um estúdio de música no Alto de S. João. A formação dessa banda foi muito importante porque surgiu com o propósito de concorrer

\footnotetext{
${ }^{6}$ Uma banda da cena punk e alternativa de Portugal que surgiu nos anos 1980: a primeira banda de Tó Trips.
} 
no Concurso de Música Moderna do Rock Rendez Vous7. Ressalve-se que o fato do Rock Rendez Vous se localizar nas imediações do Liceu potenciou a frequência de Tó naquele espaço, frequência essa determinante para a sua iniciação numa cultura rock. Já aqui se verificava a relação entre indivíduo, espaço e som. Neste ponto, adimos um outro caso, passado anos mais tarde, mas que demonstra de forma bem patente a emoção de Tó com estas vertentes da música e com o visionamento e fruição de espetáculos musicais. Assim, quando frequentou pela primeira vez o Festival de Reading, a emoção que sentiu revelou-se no próprio corpo dado que, foi nesta altura e derivado da emoção que sentiu, que se manifestou nele psoríase. Podemos desde já anotar que a hexis corporal de Tó nos remete diretamente para corporificação do típico rocker, por toda a sua apresentação e postura.

\begin{abstract}
Esses amigos meus... depois a malta formou uma banda $\left(7^{\circ}\right.$ ano unificado). Íamos ensaiar ali ao Estúdio Som, que era uma sala no Alto de S. João. E depois inscrevemo-nos no primeiro concurso... depois apareceu o Rock Rendez Vous que era lá ao pé do D. Pedro V e a malta começou a ir lá e de repente era uma coisa diferente [...]. O primeiro concerto que eu fui foi o último Sábado... fui lá ver os Xutos e Pontapés, Lena d’Água e Salada de Fruta, os Da Vinci [...] Go Graal Blues Band do Paulo Gonzo, que também foram lá tocar [risos]. Mas foi fixe! Foi a primeira vez que eu vi assim um gajo tipo punk! (Tó, 54 nos, Designer Gráfico, Músico e Compositor, 12. Ano de Escolaridade, Lisboa, informação verbal)
\end{abstract}

A reação dos pais ao seguimento por parte de Tó de uma carreira ligada à música, e ao rock, nunca foi explicitamente negativa. No entanto, estes assumiam sempre uma discursividade marcada por expectativas diferentes face ao futuro profissional do filho e um entendimento dessa ligação à música como algo passageiro, "um eterno hobby". Além do mais, no cômputo dos consumos culturais de Tó, a música ocupa (e sempre ocupou) um lugar central. Assim, os elementos relevantes desses consumos são os aspectos físicos da música, bem como a prática e audição de música per si. Desde as capas dos discos à estética, passando pelos cartazes, bilhetes de concertos, etc., percorremos

\footnotetext{
${ }^{7}$ Foi considerado como um dos espaços de música rock mais importantes em Portugal, na década de 1980. Atualmente é recordado como um lugar mítico.
} 
os principais elementos relevados por Tó. Ele é, assim, um colecionador de memorabilia do rock.

Normalmente consumo coisas em relação à música. Normalmente, aquilo que tu ouves reflete um pouco aquilo que tu és. E como a música é uma coisa importante na minha vida, tudo o que eu faço (para além de músico, sou designer - capas de discos e posters) desde que me levanto até que me deito, tem a ver um pouco com a música.

Pela música e por tudo o que esteja relacionado com música... notícias, sei lá... Gosto bué de ir aos concertos do Zé Pedro dos Xutos porque eu estou a ver o concerto ele está-me a contar histórias sobre aquele gajo que está a tocar. Eu gosto de saber esse lado da história... dos cartazes...

Gosto de estar sempre a ouvir música, gosto de descobrir coisas novas, que me falam de coisas novas. Hoje em dia sou bastante eclético, oiço de tudo. (Tó, 54 nos, Designer Gráfico, Músico e Compositor, 12. Ano de Escolaridade, Lisboa, informação verbal)

Tó assume-se também como um frequentador da cidade. Assim, nos anos 1980, aponta que havia, de fato, uma movida em torno do Rock Rendez Vous; e nos anos 1990, em torno do Johnny Guitar ${ }^{8}$. Aliás, é bem possível dizer que estamos perante uma pessoa que foi frequentadora assídua da noite na cidade, mantendo-se a par das dinâmicas musicais contemporâneas localizadas na Galeria Zé dos Bois ${ }^{9}$, no Lux $^{10}$, no Music Box ${ }^{11}$, no Maxime $^{12}$ ou no Bacalhoeiro ${ }^{13}$. Assim, Tó partilha uma lógica de clube, na medida em que frequenta lugares não apenas pelo programa anunciado, mas porque estes estão, eles próprios, relacionados com a música e com um modo de vida que o interessa. Atualmente, em Lisboa, Tó encontra cada vez menos esta lógica de clube porque,

\footnotetext{
${ }^{8}$ Johnny Guitar foi um clube de rock que marcou a primeira metade dos anos 1990 em Lisboa. Teve uma intensa programação marcada por mais de 500 espetáculos.

${ }^{9}$ Trata-se de uma associação cultural fundada em 1994 e sediada em Lisboa; o seu objetivo era promover exposições, instalações, concertos e qualquer tipo de intervenções artísticas. Mais informações: https://zedosbois.org/

${ }^{10}$ Clube noturno sediado em Lisboa. Mais informações: https://observador.pt/2020/09/03/discoteca-lux-emlisboa-reabre-esta-sexta-feira-sem-pista-de-danca-e-com-eventos-culturais/

${ }^{11}$ Inaugurado em 2006, este clube assume-se como um espaço híbrido que está entre a sala de espetáculos e um espaço de dança. Mais informações: https://musicboxlisboa.com/mb/info/

${ }^{12}$ Clube noturno sediado em Lisboa.

13 A Rua dos Bacalhoeiros é uma das mais emblemáticas da cidade de Lisboa. Mais informações: https://www.maxima.pt/prazeres/detalhe/por-que-deve-ir-a-rua-dos-bacalhoeiros-em-lisboa
} 
segundo ele, as pessoas são cada vez menos educadas para ouvir música. Tal equivale a dizer que a música aparece sempre como algo associado a um hobby, e não como algo de base, algo fundamental.

Vou-te dar um exemplo: nos anos 90, o Johnny Guitar, independentemente da banda que fosse lá, quer fosse improvisada, quer fosse metal, aquilo tinha lá sempre pessoas, mesmo que entrassem só para beber uma cerveja e viam a atuação. Havia sempre pessoas. Às vezes menos, mas zero pessoas não. Eu acho que as coisas hoje estão um pouco massificadas. Ao fim e ao cabo, quase sempre foi assim, vá lá. Às vezes costumava dizer que eram sempre os mesmos nos concertos. (Tó, 54 nos, Designer Gráfico, Músico e Compositor, $12 .{ }^{\circ}$ Ano de Escolaridade, Lisboa, informação verbal)

Quanto ao trabalho de Tó na música, apercebemo-nos de que tudo foi acontecendo, quase como por acaso, sem grande intencionalidade. No entanto, percebemos também que tal pode ser explicado através das suas redes de sociabilidade que potenciam este tipo de acontecimento passível de sere entendido desta forma. Em 1996, Tó deixa de viver na casa dos pais e passa a residir na Rua das Flores, entre o Bairro Alto e o Johnny Guitar ${ }^{14}$, e é nesta altura que surge de forma mais intensa a participação nos Lulu Blind ${ }^{15}$, banda muito influenciada pelo grunge, algo indie, muito influenciada pela sua presença no festival de Reading de 1990 onde vê o Nirvana, com Kurt Cobain, tocar de cadeira de rodas entre, outras bandas marcantes como Sonic Youth. É também neste momento que Tó se torna um frequentador habitual do Johnny Guitar sendo que esse é outro marco para a sociabilização musical, dado que foi lá que gravaram o primeiro disco de Lulu Blind e foi também através disso que começaram a fazer as primeiras partes de Xutos \& Pontapés ${ }^{16}$, adquirindo uma maior experiência e visibilidade. É ainda no Johnny Guitar que se acentua a sua vivência da noite marcada pelo consumo de álcool e um

\footnotetext{
${ }^{14}$ Tratava-se de um bar situado em Lisboa que, nos anos 1990, após o fecho do Rock Rendez-Vous se tornou na meca do rock'n'roll na cidade. Todas as bandas da época atuavam lá.

${ }^{15}$ São uma banda que nasceu em Lisboa, nos anos 1990, e que reunia músicos que tinham sido membros de outras bandas da cena punk e alternativa.

${ }^{16}$ É uma das mais emblemáticas bandas de rock portuguesa que foi criada nos finais da década de 1978. São uma das mais emblemáticas bandas portuguesas que ainda se encontra ativa.
} 
secundário consumo de drogas, ainda que nos diga que nesta altura era possível conciliar o trabalho numa agência de publicidade, o rock e as sociabilidades.

Foi importante até mesmo formação de músico e traquejo e responsabilidade.... Tocar para uma audiência maior que é logo uma experiência diferente. Não é tocar assim em salas. Mais?... Esses anos todos do Johnny Guitar, bebia bastante, era bezainas todos os dias...

Porque há esse lado de fronteira que eu tenho, que é: há o lado do curtir e há o lado da desgraça e há o lado da dependência e isso é coisa que eu detesto, estás a ver? E uma vez eu lembro-me que saímos de um concerto no Seixal e ainda fomos ao Casal Ventoso para comprar lá uma coca, e odiei aquilo. Odiei! Odiei! Odiei o Casal! Odiei ir lá à noite! Mas foi fixe ter lá ido... fui lá com um colega de banda, fomos lá... e até queria lá ir... Eu nunca tinha lá ido à noite... e odiei aquilo. Vim-me embora e disse: «isto não é para mim! Isto não sou eu! Isto não tem nada a ver comigo! Não preciso disto!». (Tó, 54 nos, Designer Gráfico, Músico e Compositor, 12. ${ }^{\circ}$ Ano de Escolaridade, Lisboa, informação verbal)

Tó é um indivíduo plural. Tal prova-se através da sua movimentação em diferentes quadros de interação associados a diferentes contextos sociogeográficos. Relaciona-se com pessoas de Benfica, o seu local de residência de infância e juventude; relaciona-se com pessoas de Alvalade mais ligadas ao punk; pessoas de Campo de Ourique mais intelectuais e arty. Face à sua atividade como músico, diz-nos que o que mais valoriza é seu lado positivo, lúdico e terapêutico, mas também o fato de ser uma via eficaz para transmitir uma mensagem. Até mesmo os seus trabalhos enquanto designer gráfico denotam a resistência e a conscientização da importância do uso das artes, como via de transmissão de mensagens empoderadoras. Se no design faz muitas concessões, por outro lado, reserva para o campo do rock a liberdade e a não concessão. Demarca-se também do lado individual dado que prefere trabalhar em grupo e fazer com que as coisas não estejam dependentes dele.

Fiquei contente, mas não estava à espera, porque aquilo era um instrumental e ainda por cima era só uma guitarra, mas como aquilo tinha muito a cena portuguesa, a malta disse: "Curto esse disco! está diferente!». E até houve uma vez que saí do estúdio e saí assim um bocado em pânico, porque eu sempre gostei de ter bandas porque é um 
conjunto de pessoas. Eu sozinho, a apresentar sozinho é uma coisa... «O quê, agora estou aqui armado em guitar hero?» [... ] E então fiquei assim bué inseguro, porque eu a primeira vez fiquei mesmo inseguro, estás a ver? Sei lá... nos Lulu Blind às vezes tínhamos bué mau prestígio, mas era um grupo e a malta fazia aquilo que queria.

E agora sozinho era uma cena... Ei estou aqui armado em guitarrista super não sei o quê, estás a ver? Nessa altura até foi a minha mulher na altura, a Lavívia, a mãe da Alice, que disse. «Continua! Isso é muito fixe e não sei o quê...». E depois o Henrique Amaro convidou-me para gravar essas cenas para o Carlos Paredes. Depois encontrei o Pedro [Gonçalves] e gravei. (Tó, 54 anos, Designer Gráfico, Músico e Compositor, $12 .^{\circ}$ Ano de Escolaridade, Lisboa, informação verbal)

A convite de Jorge Ferraz, e antes de Lulu Blind, Tó participa na banda Santa Maria Gasolina em teu Ventre! $!^{17}$ muito ligada ao noise, ao no wave, ao som do Sonic Youth. Essa experiência permite-lhe alargar os seus horizontes em termos de gêneros musicais. Com Lulu Blind fez muitos concertos de onde destaca a primeira parte de Sonic Youth. Depois de Lulu Blind, Tó começa o projeto Dead Combo, inspirado em Carlos Paredes e incentivado por Henrique Amaro. Os Dead Combo são plurais também, fruto do seu, também fortuito, mas determinante, encontro com Pedro Gonçalves.

Dead Combo tem a ver com uma coisa que é eu cansei-me... Chegou uma altura na minha vida que eu cansei-me, e principalmente quando tive a minha filha, cansei-me um bocado de andar a telefonar para as pessoas para ir ensaiar. Sei lá... estive dois anos fechado dentro de uma garagem com uns gajos que depois quando arranjei os concertos os gajos não queriam tocar ou tinham sempre não sei o quê e eu decidi fazer uma coisa sozinho. É pah, eu gosto de música e também não admito... muitas vezes é o que acontece... é que as pessoas... Eu adoro bandas! E ainda hei-de ter assim uma banda de rock! (Tó, 54 nos, Designer Gráfico, Músico e Compositor, $12 .^{\circ}$ Ano de Escolaridade, Lisboa, informação verbal)

\footnotetext{
${ }^{17}$ Uma banda portuguesa ativa entre 1986 e 1991, com temas predominantemente instrumentais. Foi uma banda pioneira na introdução do rock experimental e do ruído, misturados com influências do psicodélico e da música exploratória.
} 


\section{Os Assobios dos Lusitânia Playboys ${ }^{18}$}

Assim, é no ano de 2001 que Tó Trips conhece Pedro Gonçalves, no final de um concerto e - no meio de uma conversa - surgiu a ideia de gravarem um álbum em tributo a Carlos Paredes. Após um ano, surgem os Dead Combo e, em 2004, é lançado o primeiro álbum. É a partir desse momento que o grupo se torna num dos mais singulares e únicos na música portuguesa, no sentido em que passaram a serem vistos como uma banda de culto (TORRES, 2019). Aliás, o instrumental fortemente marcado pela guitarra portuguesa, bem como as influências de outros gêneros musicais como o blues, o jazz e o folk (PARDAL, 2019), estando presente a lógica do hibridismo cultural (REGEV, 2013), fizeram com que a banda assumisse uma posição de destaque e uma veia interventiva. 0 próprio vestuário e a apresentação da banda também merecem relevo, apresentando uma estética que faz lembrar os cowboys dos filmes de Sergio Leone (TRIPS; GONÇALVES, 2013).

Foi a partir de 2003 que a paisagem de Lisboa se alterou para sempre (TORRES, 2019), pois Tó Trips e Pedro Gonçalves, conseguiram decodificar e dar vida a uma sonoridade que ecoava pelos bairros lisboetas, conferindo-lhe um toque moderno e genuíno. Desde o primeiro álbum da banda - Vol. 1 (2004) - eleito como um dos melhores álbuns do $\mathrm{ano}^{19}$, até ao último, nomeadamente Odeon Hotel (2018) que é possível identificar um passeio pela história de Lisboa, dando conta das mudanças que pautaram a cidade e as suas sonoridades. Pensando em todos os álbuns que foram lançados pela banda, é de destacar o Lusitânia Playboys pela história intimamente ligada à calçada típica portuguesa, o som do amolador de facas e o frenesi que marcava os quotidianos, mas também o Lisboa Mulata (2011) que deu nome e cara a uma cidade inteira, apresentando uma ligação entre a imagem de um Portugal tradicional e um país cada vez mais moderno, pois:

É um álbum que respira Lisboa, que nos transporta pelas ruas apertadas de Alfama, mas ao invés de ouvirmos só o barulho do fado a ecoar por

\footnotetext{
${ }^{18}$ Título de álbum de 2008 dos Dead Combo editado pela Dead \& Company / Universal.

${ }^{19}$ Por Charlie Gillett (1942-2010), um musicólogo e radialista britânico.
} 
estas, ouvimos o respirar de um Portugal a modernizar-se entre as guitarras elétricas de Tó Trips e Pedro Gonçalves. (DIA EUROPEU..., 2020)

Aliás, quem ouve atualmente as músicas dos Dead Combo, refere sempre um sentimento nostálgico, como se o som os fizesse (re)viver uma memória que nem sabiam estar guardada. Tal é confirmado pela entrevista que a banda deu sobre o seu último álbum, vejamos:

Os nossos discos estão sempre em sintonia com a cidade de Lisboa. Este álbum, Odeon Hotel, tem a ver com a gentrificação da cidade. É o disco mais eclético, mais rock, talvez o disco menos português dos Dead Combo. Somos nós numa outra Lisboa. Uma Lisboa do final da segunda década do século XXI. (TORRES, 2019)

Existe uma Lisboa antes e depois dos Dead Combo, sendo que isso também repercute no contexto da indústria musical nacional. Desde o aparecimento da banda em 2004, há quem refira a existência de um desenho musical da cidade que, por sua vez, serve de imaginário para quem lá vive e, em especial, para aqueles que não conhecem a cidade $^{20}$. Ainda pensando na importância da banda na construção de um retrato musical da cidade de Lisboa, é de se mencionar o papel de relevo da banda na série portuguesa $\mathrm{Sul}^{21}$. Deste modo, podemos identificar a cidade como um palco de visibilidade e de concretização de diversas mudanças sociais, culturais e artísticas (GUERRA et al., 2018), no sentido em que se pretende apresentar um retrato social, envolvendo e retratando ao pormenor a realidade vivida na capital; toda a banda sonora da série passa pelas produções de Dead Combo, ou seja, podemos assim aferir a pertinência das produções artísticas e musicais na banda, servindo de acompanhamento melódico ao transporte que é feito dos espectadores para momentos específicos da série. Assim, atestamos a importância da produção musical no contexto urbano, pelo fato de possuir a capacidade de vincular identidades individuais e coletivas, pois retrata - tal como enunciamos

\footnotetext{
${ }^{20}$ Basta ter em linha de conta que o chef Anthony Bourdain, antes de falecer, no seu programa intitulado No Reservations, apresenta o roteiro gastronômico de Lisboa ao som de Dead Combo (Torres, 2019: s/p).

${ }^{21}$ Uma série inspirada no cinema noir que tem como palco a cidade de Lisboa e que retrata a investigação de um crime macabro na margem do Rio Tejo.
} 
anteriormente - sonoridades e temas conectados com a cultura. É também neste sentido que destacamos o trabalho de Tó Trips para a criação da banda sonora do filme Surdina ${ }^{22}$, pois em entrevista ao Comunidade Cultura e Arte, o mesmo refere,

Sim, a minha inspiração foi a velhice e também os locais. Aquilo passa-se em Guimarães, mas também nos arredores da cidade, há ainda muito a coisa do campo, das propriedades, ou seja, há um lado urbano e um lado rural. É uma cidade muito ligada à terra, às aldeias à volta e achei que era fixe ter um lado popular na composição, mais de memória, um lado português. (FERNANDES, 2020)

Paralelamente, verificamos nos álbuns dos Dead Combo a construção de uma paisagem sonora que se pauta pela presença de histórias e ideologias, mas também de práticas de ver e de ouvir, sendo que aqui os instrumentos utilizados assumem um papel de destaque, nomeadamente a ideia de pensarmos uma cidade através dos sons emitidos pelas cordas de uma guitarra. As suas músicas, no sentido em que criam e reforçam uma relação entre som, indivíduo e espaço, fazem com que possamos afirmar que as mesmas são ilustrativas de memórias e de vivências que se inscrevem e circunscrevem no tempo, no espaço e na cidade (BULL, 2000; TONKISS, 2003).

A banda, ao ser um projeto plural e intimamente ligado ao urbano, revela aquilo que Atkinson (2005) escrevia sobre as paisagens sonoras enquanto "aura" e "ecologia sónica", pois estas colidem com as experiências quotidianas dos ambientes urbanos. Quem ouve as músicas da banda identifica elementos intangíveis, que, na sua essência, criam um sentido de identidade que vem no seguimento de uma série de interpretações que são construídas sobre os modos como a cidade de Lisboa estava organizada. Tenhamos como exemplo a música “Esse Olhar Que Era Só Teu” do álbum Lisboa Mulata (2011), que nos transmite a ideia de um diálogo, mas também transmite sentimentos diversos como a saudade, o amor e o desamor, algo muito característico das composições musicais do fado e do uso da guitarra portuguesa. Ou ainda a música "Povo

\footnotetext{
${ }^{22}$ Um longa-metragem de Rodrigo Areias e com argumento de Valter Hugo Mãe. Trata-se de uma comédia trágica desenrolada na cidade de Guimarães que narra a história de um velho solitário que recebe a notícia de que a sua falecida mulher foi vista numa aldeia com um novo namorado.
} 
Que Cais Descalço", do álbum A Bunch of Meninos (2014) que nos remete para um cenário de abandono, de tristeza e de impotência face a um futuro que se avizinha. Trata-se da descrição de uma imagem de um povo que sofre unido, que cai, mas que se ergue e continua a caminhada. Estamos perante a ideia de um país que vive um período de crise econômica e social e, neste contexto, a música "Povo Que Cais Descalço" remete à expressão da insatisfação política, mas também incentiva a união e a fraternidade (GUERRA, 2020).

Os Dead Combo ao construírem uma paisagem sonora lisboeta criam, simultaneamente, familiaridade com o ambiente, bem como incentivam problematizações e novas formas de entender e perspectivar o espaço, ou seja, criam sentimento de pertença (WHITELEY et al., 2004). Foi no cruzamento entre a saudade de uma Lisboa que já não existe e um sonho western imaginado sobre aquilo que a cidade poderia ser que nasceu, então, a música idiossincrática dos Dead Combo, fruto de um mundo globalizado e de uma cultura híbrida (REGEV, 2013). Mesmo com as influências internacionais, a banda mostrou-se mais portuguesa do que qualquer outra. Cantavam, tocavam e construíam paisagens urbanas e sonoras reais e idealizadas (CECÍLIO, 2020; MOURÃO, 2013), que ainda hoje permanecem. E sobretudo, os Dead Combo, alinham com a definição de artivismo contemporâneo identificada por Paulo Raposo (2015. p. 3): "A sua natureza estética e simbólica amplifica, sensibiliza, reflete e interroga temas e situações num dado contexto histórico e social, visando a mudança ou a resistência. Artivismo consolida-se assim como causa e reivindicação social e simultaneamente como rutura artística - nomeadamente, pela proposição de cenários, paisagens e ecologias alternativas de fruição, de participação e de criação artística."

\section{Epílogo. Quando a Alma não é Pequena ${ }^{23}$}

\footnotetext{
${ }^{23}$ Canção integrante do álbum Vol. 2 - Quando a Alma Não É Pequena de 2006 editado pela Dead \& Company / Universal.
} 
Os Dead Combo (e Tó Trips) são uma figura central e incontornável quando pensamos nas paisagens sonoras de Lisboa. A interligação entre música e espaço urbano é o principal veículo e força impulsionadora da criação de paisagens sonoras urbanas (SCHAFFER, 1977). Também essa interligação funciona como um meio promotor de desenvolvimento territorial, ao mesmo tempo em que fomenta o fortalecimento das culturas nacionais, dos territórios, e das identidades individuais e coletivas; basta termos como exemplo as músicas que foram enunciadas ao longo do artigo. Na verdade, o percurso de Tó Trips e da banda em questão, são fruto de um circuito real e autoimaginado coletiva e individualmente face a uma cidade no passado, presente e futuro. Mais ainda, trata-se de uma cena musical (STRAW, 1991) e de uma territorialidade sônicomusical (GUERRA et al., 2018; HERSCHMANN; FERNANDES, 2016) intimamente ligada a processos de mediação e de auscultação das práticas culturais (SAMUELS et al., 2010). Aliás, podemos aferir que os Dead Combo são um exemplo tácito da aplicabilidade do conceito de paisagem sonora, no sentido em que estes acomodam um ambiente sonoro que caracteriza determinado local, por exemplo a cidade de Lisboa como um todo ou zonas específicas como as ruas estreitas de Alfama ou a vida noturna do Bairro Alto. É, então, uma resposta coletiva e individual aos ambientes, assentes em subjetividades individuais que relacionam o som, o território e o indivíduo.

A sonoridade dos Dead Combo e restantes trabalhos artísticos produzidos por Tó Trips, destacam a importância sociológica de se estabelecer uma perceção aprofundada das paisagens sonoras que demarcam o "Sul do Norte" Global, nomeadamente Portugal. Esse mix entre resistência e existência (GUERRA, 2021) que pauta o contexto português, mas também o percurso de Tó Trips e dos Dead Combo, resulta de um conjunto de condicionalismos políticos, econômicos, culturais e sociais que se impuseram. Podemos, assim, aferir que as suas produções musicais demarcam uma separação, mas também um distanciamento e uma crítica às condições de vida de uma Lisboa do passado, presente e quiçá do futuro. A luta sob a forma de música foi o caminho escolhido, no sentido em que também proporcionou a liberdade das carreiras e dos caminhos que eram trilhados. Desta forma, revelou-se a importância de se aprofundar um tipo de conhecimento teórico e empírico sobre a forma como os agentes sociais processam os sons de modos diferentes, 
de que forma estes são produzidos e, claro está, em que medida estes são categorizados dentro de um campo relacional abrangente de memórias e simbologias individuais e coletivas.

Mas Tó Trips e os Dead Combo fazem mais. Fazem com que seja impossível pensar o artivismo fora da cidade, já que é nesta que surgem os novos movimentos sociais envolvidos em lutas anticapitalistas mormente no pós-2008 (SANTOS et al., 2018). E é aqui que medra o artivismo, o qual ganhou ainda mais força após a crise econômica de 2008. Apesar de, para muitos, a arte e a política se situarem em esferas afastadas entre si, a verdade é que no nosso objeto se encontram unidas. Nesse âmbito, o artivismo de Tó Trips e dos Dead Combo propõe a recuperação da atividade artística como forma de intervenção social. Uma intervenção que balanceia entre três características: visibilidade, durabilidade e risco (GUERRA, 2019; RAPOSO, 2015).

\section{Referências}

ADHITYA, Sara. Musical Cities. Londres: UCL Press, 2017.

ATKINSON, Rowland. The aural ecology of the city: sound, noise and exclusion in the city. University of Tasmania: Housing and Community Research Unit, 2005.

BALLICO, Christina; WATSON, Allan. Music cities: evaluating a global cultural policy concept. London: Palgrave Macmillan, 2020.

BAKER, Andrea. The great music city: exploring music, space and identity. London: Palgrave Macmillan, 2019.

BARBERO, Jesus Martin. Dos meios às mediações: comunicação, cultura e hegemonia. Rio de Janeiro: Editora da UFRJ, 2003.

BEER, David. Tune out: music, soundscpaes and the urban mise-en-scène. Information. Communication \& Society, [London], v. 10, n. 6, p. 846-866, 2007.

BENNETT, Andy. Part I: Music, space and place. In: WHITELEY, Sheila; BENNETT, Andy; HAWKINS, Stan (Orgs.). Music, Space and Place: Popular Music and Cultural Identity. Ashgate: Aldershot, 2004, p. 2-8. 
BENNETT, Andy; AUTOR 1. DIY Cultures and Underground Music Scenes. Abingdon/Oxford: Routledge, 2019.

BENNETT, Andy; PETERSON, Richard. Music scenes: local, translocal, and virtual. Nashville: Vanderbilt University Press, 2004.

BENNETT, Toby. The justification of a music city: Handbooks, intermediaries and value disputes in a global policy assemblage. City, Culture and Society, [London], v.22, 2020.

BULL, Michael. Sounding Out The City: Personal Stereos and the Management of Everyday Life. Oxford: Berg, 2000.

CECÍLIO, André. Dead Combo: O adeus de quem transformou Lisboa no Velho Oeste. Sapo 24, Lisboa, 15 de fevereiro, 2020. Disponível em:

https://24.sapo.pt/vida/artigos/dead-combo-o-adeus-de-quem-transformou-lisboa-novelho-oeste. Acesso em: 19 mar. 2021.

COHEN, Sara. Rock culture in Liverpool: Popular Music in the Making. New York: Oxford University Press, 1991.

DEAD COMBO [Compositor e intérprete]. Vol 1. Lisboa: Transformadores, 2004.

DEAD COMBO [Compositor e intérprete]. Vol.2 - Quando a Alma Não É Pequena. Lisboa: Dead \& Company/Universal, 2006.

DEAD COMBO [Compositor e intérprete]. Guitars From Nothing. Leiria: Rastilho Records, 2007.

DEAD COMBO [Compositor e intérprete]. Lusitânia Playboys. Lisboa: Dead \& Company/Universal, 2008.

DEAD COMBO [Compositor e intérprete]. Lisboa Mulata. Lisboa/Leiria: Dead \& Company/Transformadores/Rastilho Records, 2011.

DEAD COMBO [Compositor e intérprete]. A Bunch of Meninos. Leiria: Rastilho Records, 2013.

DEAD COMBO [Compositor e intérprete]. Odeon Hotel. Lisboa: Sony Music, 2018.

DEAD COMBO [Compositor e intérprete]. Live Hot Clube. Lisboa: Dead \& Company, 2009. 
DEAD COMBO [Compositor e intérprete]. Live at Teatro São Luiz. Lisboa: Dead \& Company, 2014.

DENORA, Tia. Music in Everyday Life. Cambridge: Cambridge University Press, 2004.

DIA EUROPEU da música: uma viagem pela Europa através de 15 álbuns. In: ESPALHAFACTOS, Lisboa, 21 jun. 2020. Disponível em: https://espalhafactos.com/2020/06/21/diaeuropeu-da-musica-2020/. Acesso em: 17 mar. 2021.

FEATHERSTONE, Mike. Consumer culture and postmodernism. Londres: SAGE Publications, 1991.

FERNANDES, Cíntia; HERSCHMANN, Micael. Cidades Musicais. Comunicação, Territorialidade e Política. Porto Alegre: Editora Sulina, 2018.

FERNANDES, João Miguel. Entrevista. Tó Trips: “Não gostaria de voltar aos sítios onde já estive, prefiro ficar com a ideia do que vivi. Comunidades, Cultura e Arte, Lisboa, 17 de julho de 2020. Disponível em: https://www.comunidadeculturaearte.com/entrevista-totrips-nao-gostaria-de-voltar-aos-sitios-onde-ja-estive-prefiro-ficar-com-a-ideia-do-que-vivi/. Acesso em: 18 mar. 2021.

FORTUNA, Carlos. Identidades, percursos, paisagens culturais. Oeiras: Celta Editora, 1999.

FRITH, Simon. Music and identity. In: HALL, Stuart; DU GAY, Paul (Orgs.). Questions of cultural identity. London: Sage Publications, 1996, p.108-127.

GARCIA, José Sànchez; PÀMPOLS, Carles Feixa. In My Name and the Name of All People Who Live in Misery: Rap in the Wake of Revolution in tunisia and Egypt. Young, [London], v.28, n.1, p.85-100, 2020.

GILLETT, Charlie. The Sound of the City: The Rise of Rock and Roll. New York: Outerbridge \& Dienstfrey, 1970.

GUERRA, Paula. So close yet so far: DIY cultures in Portugal and in Brazil. Cultural Trends, 2021. Disponível em:

https://www.tandfonline.com/doi/abs/10.1080/09548963.2021.1877085

GUERRA, Paula. The Song Is Still a 'Weapon': The Portuguese Identity in Times of Crises. Young, [London], v.28, n.1, p.14-31, 2020.

GUERRA, Paula. Nothing is forever: um ensaio sobre as artes urbanas de Miguel Januário \pm MaisMenos \pm . Revista Horizontes Antropológicos, [São Paulo], v.25, n.55, p.1949, 2019. 
GUERRA, Paula; BITTENCOURT, Luiza; DOMINGUES, Daniel. Sons do porto: para uma cartografia sónica da cidade vivida. Cuadernos de Etnomusicologia, [Barcelona], v.12, p.184-210, 2018.

HALL, Stuart. Da diáspora: identidades e mediações culturais. Belo Horizonte: Editora UFMG, 2003.

HERSCHMANN, Micael; SANMARTIN, Cíntia Fernandes. Comunicação, música e territorialidades: repensando a relevância das cidades musicais do Rio de Janeiro. Revista LOGOS, [Rio de Janeiro], v.45, n.23, p.37-50, 2016.

HERSCHMANN, Micael; FERNANDES, Cíntia Fernandes. Música nas ruas do Rio de Janeiro. São Paulo: INTERCOM, 2014.

HERSCHMANN, Micael. Ativismo musical e desenvolvimento local. In: Políticas Culturais: formação e pesquisa. São Paulo : Itaucultural, 2012, p. 285-306.

HERSCHMANN, Micael. Cenas, Circuitos e Territorialidades Sõnico-Musicais. In: SÁ, Simone Pereira; JANOTTI, Jeder (Orgs.). Cenas Musicais. Guararema: Anadarco, 2013, p. 41-56.

HOMAN, Shane. SLAM: The music city and cultural activism. Law, Social Justice \& Global Development, [Warwick], v.1, p.1-12, 2016.

JOB, RFS; HATFIELD, Carter; PEPLOE, Taylor. Reaction to noise: the roles of soundscape, enviroscape and psychscape, USA: Fort Lauderdale, 1999.

MCLUHAN, Marshall; FIORE, Quentin. The Medium is the Message. London: Touchstone, 1989.

MOURÃO, Rui. Representações de contrapoder: performances artivistas no espaço público Português. Tese (Mestrado em Antropologia) Dissertação de mestrado. ISCTEIUL, Lisboa, 2013.

NOFRE, Jordi. Desafiando la noche neoliberal: El ocio nocturno como mecanismo de inclusón y bienestar social. Todas As Artes: Revista Luso-Brasileira de Arte e Cultura, Porto, 2(1), 48-65, 2019.

PARDAL, João. Dead Combo: um olhar sobre as cordas da boa fama. In: ESPALHAFACTOS, Lisboa, 2 out. 2019. Disponível em: https://espalhafactos.com/2019/10/02/deadcombo-um-olhar-sobre-as-cordas-da-boa-fama/. Acesso em: 19 mar. 2021.

PEREIRA, Fausta Cardoso. Dormir com Lisboa. Lisboa: Editora Imaginauta, 2020. 
RAPOSO, Paulo. “Artivismo": Articulando dissidências, criando insurgências. Cadernos de Arte e Antropologia, Salvador, vol. 4, n. 2, p. 3-12, 2015.

REIS, Ana Carla Fonseca. Cidades Criativas: Análise de um conceito em formação e da pertinência de sua aplicação à cidade de São Paulo. São Paulo: Faculdade de Arquitetura e Urbanismo. Universidade de São Paulo, 2011.

REGEV, Moti. Pop-Rock music: Aesthetic cosmopolitanism in late modernity. Cambridge: Cambridge, Polity Press, 2013.

RODRIGUES, Walter. Globalização e gentrificação: teoria e empiría. Sociologia, Problemas e Práticas, Lisboa, v.29, p.92-125, 1999.

SÁ, Simone Pereira de; JANOTTI, Jeder. Cenas Musicais. Guararema: Anadarco, 2013.

SÁ, Simone Pereira de; STRAW, Will. Cenas musicais, sensibilidades, afetos e a cidade. In: GOMES, Itania; JANOTTI, Jeder (orgs.). Comunicação e Estudos Culturais. Salvador: Edufba, 2011, p.1147-1161.

SAMUELS, David W.; MEINTJES, Louise; OCHOA, Ana Maria; PORCELLO, Thomas. Soundscapes: Toward a Sounded Anthropology. Annual Review Anthropology, [London], v.39, p.329-345, 2010.

SILVA, Augusto Santos; AUTOR 1; SANTOS, Helena. When art meets crisis. The Portuguese story and beyond. Sociologia, Problemas e Práticas, Lisboa, n. 86, p. 27-43, 2018.

SCHAFER, Murray R. Soundscape: Our sonic environment and the tuning of the world. Rochester, VT: Destiny, 1977.

SCHAFER, Murray R. In Search of concrete music. Berkeley: University of California Press, 2012.

SCHAFER, Murray R. The Soundscape: Our Sonic Environment and the Turning of the World. Rochester: Destiny Books, 1993.

SMALL, Christopher. Music of the common tongue: Survival and celebration in Afro American music. London: John Calder, 1987.

STRAW, Will. Systems of Articulation, Logics of Change: Scenes and Communication. Popular Music, Cultural Studies, London, v.5, n.3, p.368-388, 1991. 
TERRIL, Amy; DON HOGARTH, Alex Clement; FRANCIS, Roxanne. The mastering of a music city: Key elements, effective strategies and why it's woth pursuing. Toronto: IFPI \& Music Canada, 2015.

TONKISS, Fran. Aural postcards: sound, memory and the city. In: BULL, Michael; BACK, Les (orgs.). The Auditory Culture Reader. Oxford: Berg, 2003, p.303-309.

TORRES, Patrícia. Até já, Dead Combo. Vogue, Lisboa, 26 nov. 2019. Disponível em: https://www.vogue.pt/dead-combo. Acesso em: 12 mar. 2021.

TRIPS, Tó; GONÇALVES, Pedro. Dead Combo - 10 Anos de Vadiagem. Lisboa: Chiado Books, 2013.

WHITELEY, Sheila; BENNETT, Andy; HAWKINS, Stan. Music, Space and Place: Popular Music and Cultural Identity. Ashgate: Aldershot, 2004.

Recebido em: 23/03/2021 Aprovado em: 30/08/2021

Universidade do Estado de Santa Catarina - UDESC Centro de Ciências Humanas e da Educação - FAED

PerCursos

Volume 22 - Número 50 - Ano 2021 revistapercursos@gmail.com 